\title{
Comparison of Third Generation Proximal Femoral Nails in Treatment of Reverse Oblique Intertrochanteric Fractures
}

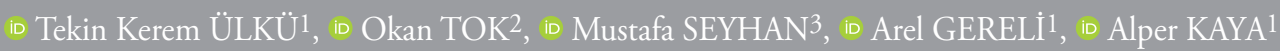

${ }^{1}$ Acıbadem University Faculty of Medicine, Department of Orthopedics and Traumatology, İstanbul, Turkey

${ }^{2}$ Lütfiye Nuri Burat Public Hospital, Clinic of Orthopedics and Traumatology, İstanbul, Turkey

${ }^{3}$ Acibadem University Faculty of Health Sciences, Clinic of Orthopedics and Traumatology, İstanbul, Turkey

\begin{abstract}
Objective: The purpose of the study is to evaluate the treatment results of reverse oblique AO/OTA 31A1 fractures that have highly mechanical instability risk with two third generation intramedullary nails.

Methods: Twenty-eight patients ( 8 men, 20 women) treated by third generation proximal femoral nails [proximal femoral anti-rotation (PFNA) ${ }^{\circ}$ or Intertan ${ }^{\circ}$ ] followed minimum one year were included. Average age was 65.0 (31-93) years. Clinical and radiological results, screw migration at one year and complications were recorded.

Results: Mean operation time was 72.2 and 72.5 minutes, flouroscopy time was 64.4 and 64.7 seconds, mobilisation time was 2.1 and 2.2 days, full weight bearing time was 8.6 and 8.5 weeks, tip-apex distance was 20.1 and $20.2 \mathrm{~mm}$, fracture healing time was 10.5 and 10.2 weeks, Harris hip score at one year was 80.5 and 83.5, neck-shaft angle difference at one year was 1.6 and $1.1 \mathrm{~mm}$, screw migration at one year was found in 10 and 3 patients and mean migration distance was 3.1 and $0.4 \mathrm{~mm}$ for PFNA and Intertan nails respectively. No complications recorded that needs secondary intervention. Fracture healing obtained in all patients.
\end{abstract}

Conclusion: Reverse oblique intertrochanteric fractures can be effectively treated with third generation intramedullary nails. More screw migration was seen in PFNA than Intertan nails after the operation in this study.

Keywords: Reverse oblique fracture, instability, 3. generation, proximal femoral nail

\section{Introduction}

In older patients with intertrochanteric fractures, the main target is immediate surgical intervention and faster rehabilitation $(1,2)$. Dynamic nails, proximal femur nails and fixed-angle proximal femur locking plates are the most common treatment options. Osteosynthesis material must be strong enough to carry loads because in the older population, restriction of load-carrying can be difficult.

Since reverse obliquity fractures are often accompanied by lateral femoral cortex fracture, they are more likely to have instability and are classified as $31 \mathrm{~A} 3$ according to the AO/OTA classification $(3,4)$. Dynamic hip nails, which are the gold standard for stable fractures, are generally not considered suitable for such fractures (5-8). Whereas intramedullary hip nails are biomechanically stronger and more reliable (5-8).

Since problems such as $\mathrm{Z}$ effect and implant failure were observed in the second generation proximal femur nails, third generation hip nails with superior implant design and stability were introduced. There are studies that support the reliability of third generation nails especially in unstable trochanteric fractures (9-12). In this study, the clinical and radiological results of patients treated

Address for Correspondence: Tekin Kerem ÜLKÜ, Acıbadem University Faculty of Medicine, Department

Cite this article as: Ulkü TK, Tok O, Seyhan M, Gereli A, Kaya A. Comparison of Third Generation Proximal Femoral Nails in Treatment of Reverse Oblique Intertrochanteric Fractures. Bezmialem Science 2019;7(4):271-5. 
with two different third generation proximal hip nails in $\mathrm{AO} /$ OTA 31 A3 class reverse obliquity fractures were retrospectively compared.

\section{Methods}

Between January 2006 and January 2012, 33 patients with AO/ OTA 31 A3 reverse obliquity fractures were treated by surgical method. Since 1 patient was a patient with multiple traumas, 1 patient had a pathological fracture, 1 patient was not followed up and 2 patients died, they were not included in the study. Twentyeight patients were followed for a period of at least 1 year. Of 28 patients, $20(71.4 \%)$ were female and $8(28.6 \%)$ were male. The median age was 65 (31-93) years. The average follow-up duration was 19.4 months (12-60). All patients underwent pelvic anteroposterior (AP) X-ray and hip AP-lateral X-ray of the operated side on the first postoperative day. Patients were followed up with the same radiological imaging methods and physical examination on the $1^{\text {st }}, 2^{\text {nd }}, 3^{\text {rd }}, 6^{\text {th }}, 12^{\text {th }}$ months after surgery and then annually (Tables 1 and 2).

\begin{tabular}{|c|c|c|c|}
\hline & $\mathrm{PFNA}^{\circledR}$ & Intertan ${ }^{\circledR}$ & Total \\
\hline & 16 & 12 & 28 \\
\hline Fall & $13(81.3 \%)$ & 9 (75.0\%) & $22(78.6 \%)$ \\
\hline Sports injury & $2(12.5 \%)$ & $0(0.0 \%)$ & $2(7.1 \%)$ \\
\hline Falling from high & $1(6.3 \%)$ & $2(16.7 \%)$ & $3(10.7 \%)$ \\
\hline Traffic accident & $0(0.0 \%)$ & $1(8.3 \%)$ & $1(3.6 \%)$ \\
\hline
\end{tabular}

Table 2. AO/OTA subgroup analysis of patients

\begin{tabular}{|l|l|l|l} 
& PFNA $^{\circledR}$ & Intertan $^{\circledR}$ & Total \\
\hline Fracture type & 16 & 12 & 28 \\
\hline A3-1 & $2(12.5 \%)$ & $1(8.3 \%)$ & $3(10.8 \%)$ \\
\hline A3-2 & $5(31.3 \%)$ & $4(33.3 \%)$ & $9(32.1 \%)$ \\
\hline A3-3 & $9(56.3 \%)$ & $7(58.3 \%)$ & $16(57.1 \%)$ \\
\hline
\end{tabular}

\begin{tabular}{|l|l|l|l} 
& PFNA $^{\circledR}$ & Intertan & Total \\
\hline Fracture type & 16 & 12 & 28 \\
\hline A3-1 & $2(12.5 \%)$ & $1(8.3 \%)$ & $3(10.8 \%)$ \\
\hline A3-2 & $5(31.3 \%)$ & $4(33.3 \%)$ & $9(32.1 \%)$ \\
\hline A3-3 & $9(56.3 \%)$ & $7(58.3 \%)$ & $16(57.1 \%)$ \\
\hline
\end{tabular}
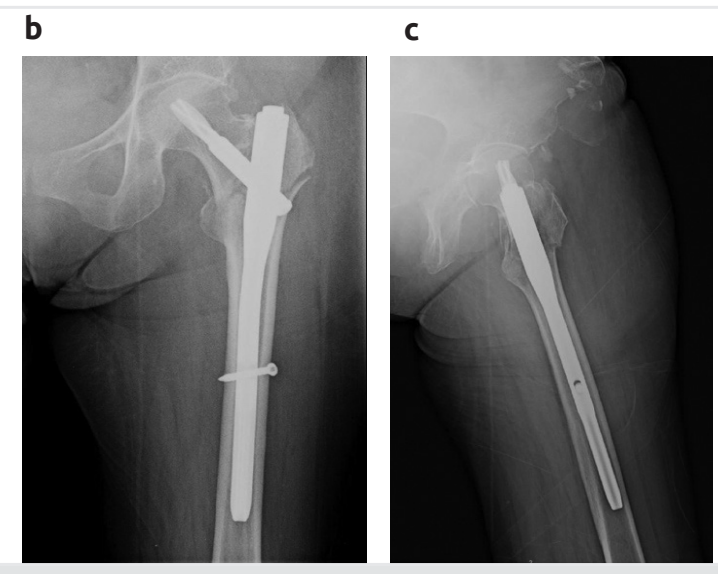

All operations were performed by the same surgeon with the same closed technique on the traction table. Sixteen patients received proximal femoral nail anti-rotation $\left(\mathrm{PFNA}^{\oplus}\right.$-Synthes, Oberdorf, Switzerland) (Figure 1) and 12 patients received intertrochanteric antegrade nail (Intertan ${ }^{\oplus}$-Smith-Nephew, Memphis, TN) (Figure 2). In PFNA ${ }^{\oplus}$ cases, nails were $24 \mathrm{~cm}$ long and $130^{\circ}$ angled. In Intertan $^{\oplus}$ cases, nails were $20 \mathrm{~cm}$ long and $130^{\circ}$ angled. In 2 cases where the neck-shaft angle was low on the intact side, $125^{\circ}$ Intertan $^{\circledast}$ nails were preferred.

Total operation and fluoroscopy times, mobilization and total load delivery times, tip-apex distances and fracture recovery times were recorded during operations. Also, Harris hip score ( $1^{\text {st }}$ year) (13), neck-shaft angle change in the first year, nail migration in the first year and complications were noted. Complications requiring revision surgery, such as deep infection, inability to heal and shortening by more than $15 \mathrm{~mm}$, were considered major complications.

Calculations were performed on AP-Lateral X-rays of the pelvis and hip AP-lateral X-rays in the postoperative $1^{\text {st }}$ day and $1^{\text {st }}$ year. Neck-shaft angle was calculated on pelvis AP X-rays and tip-apex distance was calculated on hip AP-lateral X-rays. Lateral protrusion difference between the postoperative first day and the postoperative first year of dynamic screw was considered as nail migration in the first year. The functional evaluation of the patients in the first year was performed using Harris hip score. Patients' complaints, such as feeling the presence of the nail and restlessness, were considered as implant discomfort.

All patients underwent proper mobilization, exercise program, standard antibiotics and thromboembolism prophylaxis after surgery. All patients were allowed to give as much burden as could be tolerated. Walkers and crutches were not used when the patient did not need them. For our study, Acıbadem University ATADEK ethics committee approved the meeting dated 22.12.2016 with the decision number 2016-/20/15.
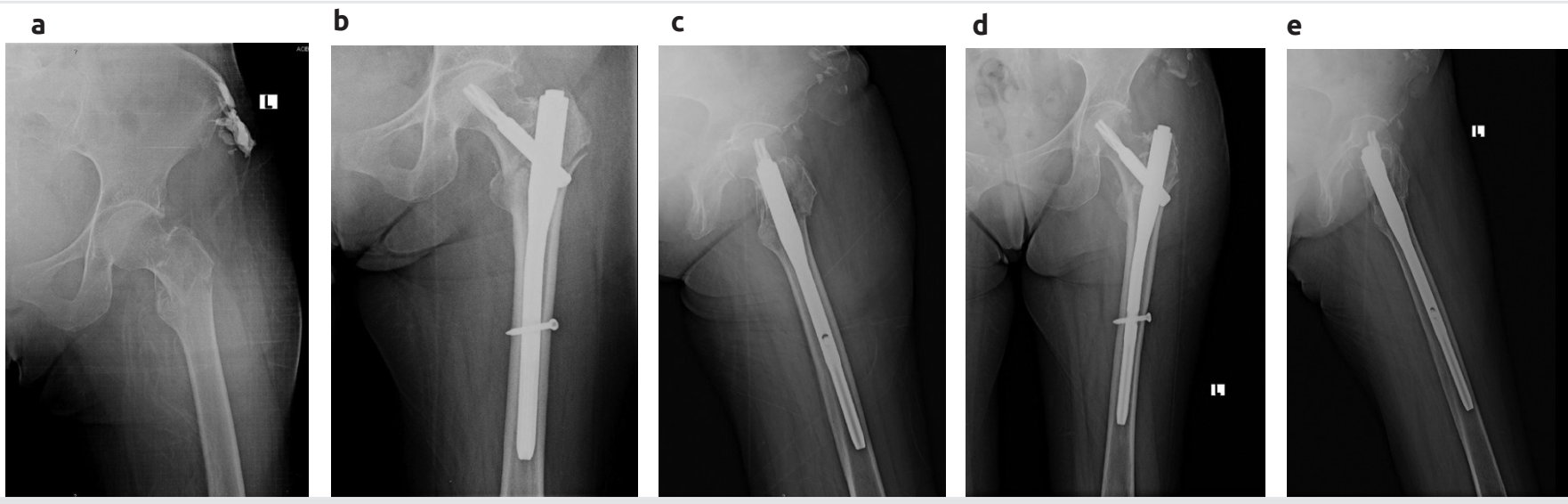

Figure 1. A 71-year-old female patient had a history of fall. (a) Third generation PFNA® (Synthes) was applied to the patient who was diagnosed as having a type AO 31 A3 fracture with impaired lateral cortex integrity. Early post-operative x-rays (b,c) and $\mathrm{x}$-rays in the first year $(\mathrm{d}, \mathrm{e})$ are shown 


\section{Statistical Analysis}

In our study, SPSS software was used for all statistical analyses. The normal distribution of the data was analyzed using the Kolmogorov-Simirnov test. During the analysis of data other than descriptive statistical methods, quantitative data showing normal distribution were compared using student tests. Data that did not show normal distribution were also compared using the Mann-Whitney U test. Qualitative data were analyzed using chi-square and Fisher exact chi-square tests. Significance level was considered as $\mathrm{p}<0.05$.

Written and oral informed consents of all patients included in the study were obtained.

\section{Results}

There was no statistically significant difference between nails in terms of operation times $(p>0.05)$. In addition, there were no differences between nails in terms of fluoroscopy times, mobilization and total load delivery times, tip-apex distances, fracture recovery times and Harris hip scores in the first year. There was also no difference between nails in terms of the neck-shaft angle change in the first year. Mean nail migration in the first year was statistically significantly different in PFNA ${ }^{\oplus}$ compared with Intertan ${ }^{\circledast}$.

In four cases ( 2 with Intertan ${ }^{\circledast}, 2$ with PFNA $^{\circledast}$ ), hematoma formation occurred laterally in the thigh. In 3 of these cases, the hematoma was spontaneously resorbed while in 1 patient who underwent Intertan ${ }^{\oplus}$, drainage was required with local anesthesia. Four patients ( 2 with Intertan ${ }^{\circledast}, 2$ with $\mathrm{PFNA}^{\oplus}$ ) felt discomfort due to the implant, yet in none of these patients implant was needed to be removed. Two patients (1 with Intertan $^{\oplus}$, 1 with PFNA $^{\oplus}$ ) suffered from long-term groin pain. Healing of fracture was achieved in all patients. None of the patients had major complications, such as infection and dislocation. In our study, a

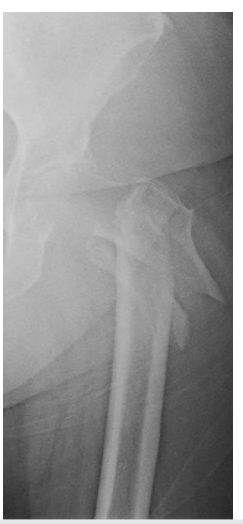

C

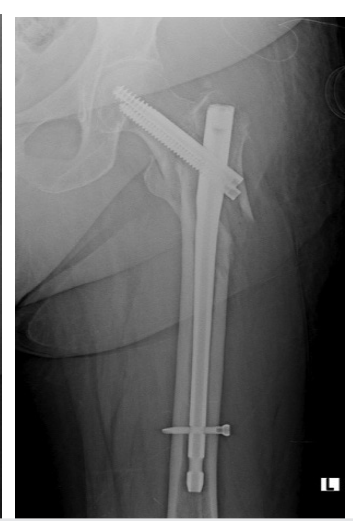

d

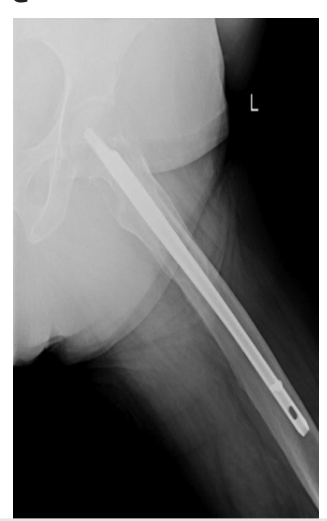

e

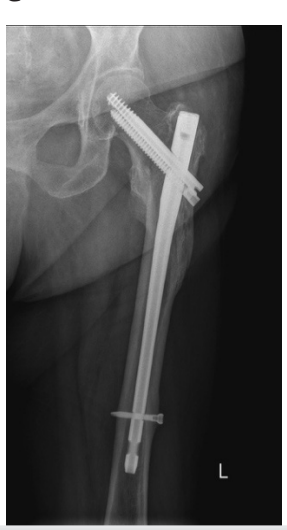

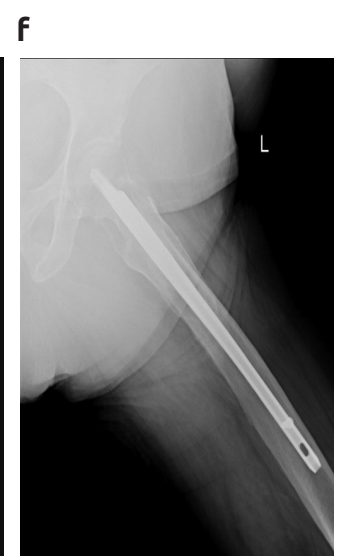

Figure 2. Third generation Intertan $®$ (Smith and Nephew) was applied to a 58-year-old female patient who was diagnosed with type AO 31 A3 fracture with impaired lateral cortex and trochanter minor integrity (a,b). Early post-operative x-rays (c,d) and $x$-rays in the first year $(e, f)$ are shown

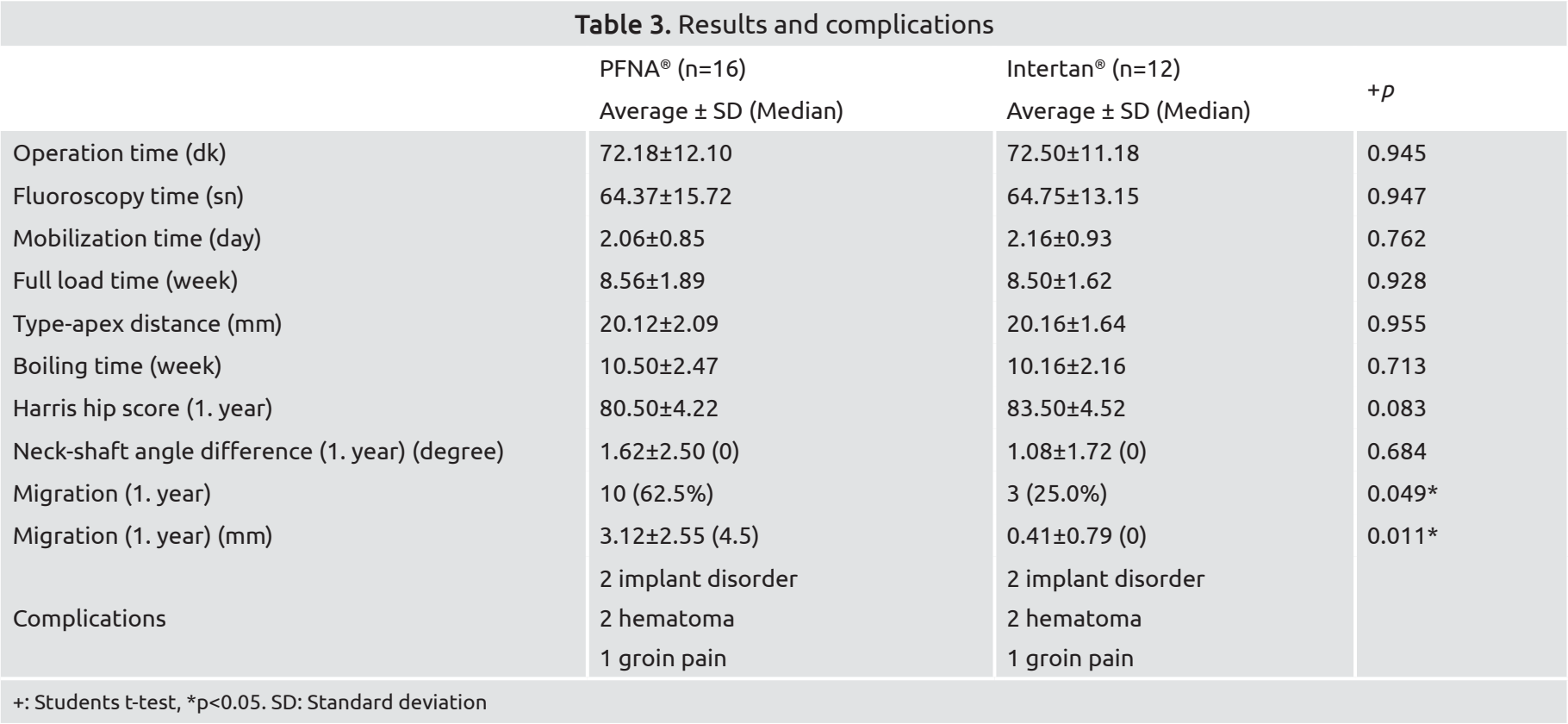


first year control X-rays showed nail migration in 3 (25\%) of 12 patients with Intertan ${ }^{\circ}$ and 10 of 16 patients with PFNA ${ }^{\circ}$. Mean nail migration was measured as $3.1 \mathrm{~mm}$ for $\mathrm{PFNA}^{\circ}$ and $0.4 \mathrm{~mm}$ for Intertan ${ }^{\circledast}$ (Table 3).

When mean nail migration was statistically compared, there was significant difference in favor of Intertan ${ }^{\oplus}$ in terms of both patient number and migration distance. However, nail migration in the PFNA ${ }^{\bullet}$ group did not result in re-operation. No patients from either group felt clinically leg shortening.

\section{Discussion}

Early mobilization is very important in trochanteric femur fractures in elderly patients (1-3). Since mobilization without giving load is difficult in older patients, osteosynthesis material must be strong enough to share the load.

Reverse obliquity trochanteric fractures have potential to lead to mechanical instability. Lateral cortex fractures of the proximal femur are a major cause of instability $(4,14)$. Implants used to treat these fractures should support the lateral cortex, preventing instability. Therefore, dynamic hip nails are not recommended in reverse obliquity trochanteric fractures, and intramedullary hip nails are preferred in treatment (15-17).

In reverse obliquity intertrochanteric fractures, older generation intramedullary hip nails have been applied relatively more successfully than alternatives. However, screw slip has become a common problem in the second generation hip nails, where 2 screws are placed in the femoral head (18). Although the cause is not known for certain, one of the 2 lag screws sent to the femoral head shows backward migration. The other screw also shows migration to proximal side ( $\mathrm{Z}$ effect). This has become a significant disadvantage in the second generation proximal femur nails. Park et al. (19) reported that in 4 of 21 cases with proximal femoral nails, the femoral nail showed migration, and 3 of them required revision surgery. The PFNA ${ }^{\circ}$ and Intertan ${ }^{\circ}$ used in our study are also third generation proximal femur nails.

Implant selection has been highlighted as critically important in the successful treatment of reverse obliquity hip fractures, with proper placement of the chosen implant and good reduction as a whole $(20,21)$.

In stable trochanteric fractures, usually longitudinal traction and internal rotation are sufficient for adequate reduction. However, in reverse obliquity fractures, these maneuvers may not be sufficient for reduction because the proximal components, including the trochanter major, remain in the lateral. Sometimes, reduction loss can occur when placing the nail. When we encountered this problem in our study, reduction was made using Steinmann pin and spike pusher and closed technique was applied in all cases. Reduction with Steinmann pin was applied percutaneously.

Another cause of reduction loss is the false trochanteric entry site (16). This crucial step should be applied without error, because it is very important to maintain reduction and to place the implant correctly. Therefore, the ideal entry location should be determined even if it causes more radiation exposure with repeated procedures. Along with the placement of nails, determining the bone entry location was the most time-consuming stage in our surgeries, resulting in radiation exposure.

One of the most useful methods for determining the accuracy of the implant position is the measurement of the tip-apex distance defined by Baumgaertner et al. (20). The tip-apex distance is suggested to be below $25 \mathrm{~mm}$. Many studies confirm that this is important for successful surgery and reduces the risk of implant failure $(19,20)$. For this reason, the position of the hip nail is just as important as the ideal bone entry location. This step should not be skipped and should be applied until the optimal position is achieved.

In all our cases, the tip-apex distance was below $25 \mathrm{~mm}$. None of the patients had problems with implant failure. Our search for the ideal bone entry location and hip nail position naturally increased our fluoroscopy time. Our average fluoroscopy time was 64.5 seconds (64.4 s for PFNA', $64.7 \mathrm{~s}$ for Intertan ${ }^{\oplus}$ ).

If the gap between the proximal and distal main parts does not close and adequate compression is not achieved, the hip nail tends to slip backwards and impaction occurs when the patient gives load. This occurs more frequently with PFNA ${ }^{\circ}$. Due to its strong compression capacity, the Intertan ${ }^{\bullet}$ nail does not leave large enough space for impaction to occur. In our study, 3 (25\%) of the 12 patients with Intertan ${ }^{\circ}$ had nail migration, while 10 of the 16 patients with $\mathrm{PFNA}^{\circ}$ had this migration. After 1 year, mean nail migration difference was found statistically significant for PFNA $(\mathrm{p}<0.05)$. Mean nail migration was $3.1 \mathrm{~mm}$ for $\mathrm{PFNA}^{\oplus}$ and $0.4 \mathrm{~mm}$ for Intertan ${ }^{\circ}$. On the other hand, none of the $\mathrm{PFNA}^{\circ}$ migrations required revision surgery.

Although the complication rate was $35.7 \%$ in our study (31.2\% in PFNA $^{\circ}$ and $41.7 \%$ in Intertan ${ }^{\circ}$ ), all of these complications were minor complications. Three were reversibl hematomas. Four of them were implant discomfort that did not require extraction, and 2 were spontaneous groin pain. None of the other complications required revision, except for one case that required hematoma drainage under local anesthesia. In all cases, fracture healing was achieved.

\section{Study Limitations}

The minimum follow-up period of our study was 1 year and the number of patients was low.

\section{Conclusion}

According to our assessment, reverse obliquity trochanteric fractures can be successfully treated using third generation intramedullary hip nails such as $\mathrm{PFNA}^{\circ}$ and Intertan ${ }^{\circ}$.

Intertan $^{\circ}$ nail reduces the risk of nail migration because it provides strong compression. As a result, implant selection, ideal entry location determination, ideal nail positioning and surgical technique are important to achieve successful results. 


\section{Ethics}

Ethics Committee Approval: For our study, Acrbadem University ATADEK ethics committee approved the meeting dated 22.12.2016 with the decision number 2016-/20/15.

Informed Consent: Since our study was retrospective, no consent was obtained from the patients.

Peer-review:: Externally peer-reviewed.

\section{Authorship Contributions}

Concept: T.K.Ü., O.T., M.S., Design: T.K.Ü., A.G., Data Collection or Processing: T.K.Ü., M.S., Analysis or Interpretation: A.K., A.G., O.T., Literature Search: O.T., T.K.Ü., Writing: T.K.Ü., O.T., M.S.

Conflict of Interest: No conflict of interest was declared by the authors.

Financial Disclosure: The authors declared that this study received no financial support.

\section{Kaynaklar}

1. Sener M, Onar V, Kazımoğlu C, Yağdi S. Mortality and morbidity in elderly patients who underwent partial prosthesis replacement for proximal femoral fractures. Eklem Hastalık Cerrahisi 2009;20:11-7.

2. Weller I, Wai EK, Jaglal S, Kreder HJ. The effect of hospital type and surgical delay on mortality after surgery for hip fracture. J Bone Joint Surg Br 2005;87:361-6.

3. Rodop O, Mahiroğulları M, Tırmık Ü, Keklikçi K, Sen H. The increasing incidence of intertrochanteric fractures synchronous with older age. Eklem Hastalık Cerrahisi 2009;20:131-5.

4. Min WK, Kim SY, Kim TK, Lee KB, Cho MR, Ha YC, et al. Proximal femoral nail for the treatment of reverse obliquity intertrochanteric fractures compared with gamma nail. J Trauma 2007;63:1054-60.

5. Jacobs RR, McClain O, Armstrong HJ. Internal fixation of intertrochanteric hip fractures: a clinical and biomechanical study. Clin Orthop Relat Res 1980;146:62-70.

6. Nuber S, Schonweiss T, Ruter A. Stabilisation of unstable trochanteric femoral fractures. Dynamic hip screw (DHS) with trochanteric stabilisation plate vs. proximal femur nail (PFN). Unfallchirurg 2003;106:39-47.

7. Parker MJ, Handoll HH. (2008) Gamma and other cephalocondylic intramedullary nails versus extramedullary implants for extracapsular hip fractures in adults. Cochrane Database Syst Rev 2010;16:CD000093.

8. Cheema GS, Rastogi A, Singh V, Goel SC, Mishra D, Arora S. Comparison of cutout resistance of dynamic condylar screw and proximal femoral nail in reverse oblique trochanteric fractures: A biomechanical study. Indian J Orthop 2012;46:259-65.

9. Simmermacher RK, Ljungqvist J, Bail H, Hockertz T, Vochteloo AJ, Ochs $\mathrm{U}$, et al. The new proximal femoral nail antirotation (PFNA) in daily practice: results of a multicentre clinical study. Injury 2008;39:932-9.

10. Soucanye de Landevoisin E, Bertani A, Candoni P, Charpail C, Demortiere E. Proximal femoral nail antirotation (PFN-ATM) fixation of extra-capsular proximal femoral fractures in the elderly: retrospective study in 102 patients. Orthop Traumatol Surg Res 2012;98:288-95.

11. Sahin S, Ertürer E, Oztürk I, Toker S, Seçkin F, Akman S. Radiographic and functional results of osteosynthesis using the proximal femoral nail antirotation (PFNA) in the treatment of unstable intertrochanteric femoral fractures. Acta Orthop Traumatol Turc 2010;44:127-34.

12. Yaozeng X, Dechun G, Huilin Y, Guangming Z, Xianbin W. Comparative study of trochanteric fracture treated with the proximal femoral nail anti-rotation and the third generation of gamma nail. Injury 2010;41:1234-8.

13. Harris WH. Traumatic arthritis of the hip after dislocation and acetabular fractures: treatment by mold arthroplasty. An end-result study using a new method of result evaluation. J Bone Joint Surg Am 1969;51:737-55.

14. Kokoroghiannis C, Aktselis I, Deligeorgis A, Fragkomichalos E, Papadimas D, Pappadas I. Evolving concepts of stability and intramedullary fixation of intertrochanteric fractures--a review. Injury 2012;43:686-93.

15. Yılmaz E, Karakurt L, Güzel H, Serin E. Evaluation and treatment results with the 95 degree AO/ASIF angular plate in subtrochanteric femur fractures. Joint Dis Rel Surg 2005;16:42-8.

16. Bredbenner TL, Snyder SA, Mazloomi FR, Le T, Wilber RG. Subtrochanteric fixation stability depends on discrete fracture surface points. Clin Orthop Relat Res 2005;432:217-25.

17. Ozkan K, Eceviz E, Unay K, Tasyikan L, Akman B, Eren A. Treatment of reverse oblique trochanteric femoral fractures with proximal femoral nail. Int Orthop 2011;35:595-8.

18. Schipper IB, Steyerberg EW, Castelein RM, van der Heijden FH, den Hoed PT, Kerver AJ, et al. Treatment of unstable trochanteric fractures. Randomised comparison of the gamma nail and the proximal femoral nail. J Bone Joint Surg Br 2004;86:86-94.

19. Park SY, Yang KH, Yoo JH, Yoon HK, Park HW. The treatment of reverse obliquity intertrochanteric fractures with the intramedullary hip nail. J Trauma 2008;65:852-7.

20. Baumgaertner MR, Curtin SL, Lindskog DM, Keggi JM. The value of the tip-apex distance in predicting failure of fixation of peritrochanteric fractures of the hip. J Bone Joint Surg Am 1995;77:1058-64.

21. Uzun M, Ertürer E, Oztürk I, Akman S, Seçkin F, Ozçelik IB. Longterm radiographic complications following treatment of unstable intertrochanteric femoral fractures with the proximal femoral nail and effects on functional results. Acta Orthop Traumatol Turc 2009;43:457-63. 